\title{
Media, Politics and Climate Change: Towards a New Research Agenda
}

\author{
Alison Anderson* \\ School of Law and Social Science, University of Plymouth
}

\begin{abstract}
Climate change is one of the most pressing issues of our time, and the media have been demonstrated to play a key role in shaping public perceptions and policy agendas. Journalists are faced with multiple challenges in covering this complex field. This article provides an overview of existing research on the media framing of climate change, highlighting major research themes and assessing future potential research developments. It argues that analysis of the reporting of climate science must be placed in the wider context of the growing concentration and globalization of news media ownership, and an increasingly 'promotional culture', highlighted by the rapid rise of the public relations industry in recent years and claims-makers who employ increasingly sophisticated media strategies. Future research will need to examine in-depth the targeting of media by a range of actors, as well as unravel complex information flows across countries as media increasingly converge.
\end{abstract}

\section{Introduction}

Climate science is a deeply contested area. There is considerable competition among (and between) scientists, industry, policymakers and non-governmental organisations (NGOs), each of whom is likely to be actively seeking to establish their particular perspectives on the issues as the one to be adopted. Since the mid-1990s, there has been mounting consensus among scientists about the role of human influence on the global climate. However, there is considerable disagreement over the nature of its effects, how best to tackle the problem and who needs to be involved. The media play a crucial role in framing the scientific, economic, social and political dimensions through giving voice to some viewpoints while suppressing others, and legitimating certain truth-claims as reasonable and credible. While media have been shown to play a key role in framing climate change, the effects are complex and dynamic and there is no straight forward relationship between information campaigns and behaviour change (Dunwoody 2007; Stamm et al. 2000).

This article sets out to introduce and map the interdisciplinary field of research on the media and climate change, highlighting major conceptual frameworks and key findings thus far. Ulrich Beck's work, most notably 
Risk Society (1992), has drawn attention to the nature of 'manufactured risks' in contemporary society - potentially far more catastrophic and far-reaching than 'natural hazards' - but offers insufficient empirical detail on the precise role of the media in communicating environmental risks. However, until relatively recently, mainstream sociology has tended to overlook climate change as an issue worthy of attention (see Lever-Tracy 2008). Accordingly, this article seeks to demonstrate how climate change connects with key debates within sociology concerning knowledge, risk and power and why it is of central importance and relevance for the discipline. In particular, it examines the merits of three major analytical approaches: political economy, structuralism and culturalism. Given the wide ranging multi-disciplinary nature of the area, this review is inevitably limited in scope and draws especially upon US and UK contexts - where much of the research has been conducted. Throughout the piece, I make reference to different strands of the literature that readers may follow according to their particular interests. The article starts off by providing an overview of previous studies in this area, highlighting their principal strengths and weaknesses, and finally concludes by addressing new developments and possibilities for future research.

\section{Issue attention cycles}

There is a relatively long history of research into the role of the media in reporting environmental issues, but it wasn't until the 1990s that we began to see the emergence of a range of studies focusing specifically upon climate change. Recent years have witnessed increasing interest among scholars from a range of disciplines in investigating how the media are reporting anthropogenic climate change. Some are snapshot studies (e.g. Antilla 2005; Hulme 2007), while others attempt to track the development of issues over a considerable length of time (e.g. Boykoff 2007b; Carvalho and Burgess 2005). Since 2000, the associated risks have been treated with greater urgency as the topic has risen up the political agenda, and journalists have increasingly made links between dramatic weather events (such as floods and heat waves) and global climate change (Carvalho and Burgess 2005). Past studies suggest that reporting was often affected by journalists' lack of knowledge of the issues (e.g. Wilson 2000a). Coverage has been variable; whilst some accounts have hampered accurate representation of climate science other reporting has been more mixed (Boykoff and Roberts 2007). Studies suggest that in general the media have tended to provide relatively little discussion of adaptation to climate change (which may be anticipatory or reactive) and instead concentrated upon less radical mitigation measures in the reduction of greenhouse gases released into the atmosphere (Boykoff and Roberts 2007).

Many of the studies mentioned above usefully drawn attention to the ebbs and flows in reporting climate change over time. They have helped 
to establish how much news media attention has been devoted to climate change since the late 1980s. Up until the mid-1980s, there was relatively sparse discussion of global warming within national print media. The late 1980s saw the first sharp rise in coverage in the British and US national daily newspapers as the issues became increasingly politicized (Boykoff and Boykoff 2004; Carvalho and Burgess 2005; Wilkins 1993). Whilst the United States was experiencing a drought and record high temperatures in the summer of 1988, James Hansen testified to a Congressional hearing that he was $99 \%$ confident that a long-term trend towards global warming was underway. That September, the former British Prime Minister Mrs Thatcher made her famous 'green' speech to the Royal Society, propelling the issue further up the agenda (see Anderson 1997). During the mid to late 1980s, a scientific discourse had prevailed with climate change scientists appearing as the principal sources for news stories. Following Mrs Thatcher's intervention, scientists lost definitional control of the debate as political actors increasingly sought to shape the agenda (Carvalho and Burgess 2005). A similar transformation in the discursive construction of climate change also appears to be evident with regards to the US and German elite national press over this period (Trumbo 1996; Weingart et al. 2000).

Between 1991 and 1996, here was a generally sharp fall in national press coverage as editorial fatigue set in and competing issues (principally the economic down turn and the war in Iraq) were perceived as having greater urgency, despite a brief blip in 1995 at the time of the release of the IPCC report (Anderson and Gaber 1993; Boykoff and Boykoff 2007; Carvalho and Burgess 2005). Following this decline, there was a second steep rise in coverage between 1997 and 2003, as the impacts of climate change were brought closer to home (Boykoff 2008; Boykoff and Boykoff 2007), though one study (restricted to examining headline coverage in the British 'quality' and 'tabloid' newspapers) found a 'fairly limited' amount of coverage between 1996 and 2000 (see Gavin 2007: 3). There is much less research evidence about television news coverage over this period. However, one study found that compared to the 1970s and the 1980s, where there were only a small number of stories, the three US television networks broadcast in the region of 100 news stories on global warming between 1990 and 1999 (Sachsman 2000).

Peaks in coverage over this time period can be directly related to important policy events such as the Kyoto Protocol in 1997. This generated a significant amount of news media coverage and there was a very large media presence (over 3,500 journalists and in excess of 400 media organisations from 160 countries; Leggett 2001 cited in Boykoff and Roberts 2007). However, the surge of interest was relatively short-lived. Alex Kirby, former Environment Correspondent for BBC News, commented: 'Alarming or not, climate change is becoming an increasingly hard subject to sell in much of the media ... Editors are simply bored with what they think is an old story they have heard before.' (Kirby 2001) 
However, between 2003 and 2006, there was a steady increase in attention among the opinion-leading newspapers in the United States, with an even more marked rise in the United Kingdom (Boykoff 2007a; Boykoff and Roberts 2007: 40-1). The release of Al Gore's film, An Inconvenient Truth, clearly played a part in generating the rise in coverage in 2006. Over this period, there was also an increase in coverage in Australia/New Zealand, the Middle East, Asia, Eastern Europe and South Africa, though again this was less steep than in the United Kingdom (Boykoff and Roberts 2007: 39). Ironically, there has been comparatively little media coverage of climate change in developing countries; yet, they are likely to suffer the worst effects (Painter 2007). In 2006, there was four times as much coverage of climate change issues in the UK prestige press than there was in 2003. Whilst in the United States over the same period, coverage increased in the elite national press by roughly two and a half times (Boykoff and Boykoff 2007b).

In the United Kingdom, many of the red-top mass circulation newspapers also began to give the issues growing coverage. For example, in September 2006, Britain's highest circulating daily newspaper, The Sun, launched its own 'Go Green with the Sun' campaign. Previously, the newspaper's coverage of climate changes issues was low key and sporadic. Between October 2000 and the end of December 2006, The Sun and its Sunday counterpart, The News of the World, only carried 18 headline stories on global warming (Gavin 2007).

Although environmental issues were just one of the topics of media interest that Down's issue-attention cycle explored, many scholars have drawn upon this model to explain the rise and fall of interest in climate change (e.g. Trumbo 1996; McComas and Shanahan 1999; Newell 2000). Downs (1972) suggests that social issues typically go through a cycle of fervent interest followed by increasing boredom. In general, Downs argues that an issue is likely to fade from media interest if its dramatic/entertainment value decreases, if it no longer affects everyone, or if it is no longer in the interests of power holders in society and will involve major upheaval and costs. However, he predicted that environmental issues are unlikely to quickly enter the 'post-problem' stage because of their intrinsic qualities (see Anderson 1997).

The problem with Downs's model is that it is too linear and inflexible. His approach tends to focus narrowly upon a limited number of fora, or arenas of influence, namely: the media and public agendas (Hilgartner and Bosk 1988). We should not underestimate the role of political institutions, NGOs, the wider political culture and the scientific community in defining the important issues of the moment. None of these public arenas are discrete units; they encompass a wide range of overlapping platforms employing different strategies and targeting a diverse range of audiences. This 'one model fits all' approach tends to downplay the complexity of public debates. An extremely diverse range of problems may be included under the heading of 'environmental' issues and, within cycles of issue attention, their fate is 
determined by a multitude of factors (Anderson 1997: 30-2). The model fails to account for differing levels of attention to an issue accorded by different media outlets. Moreover, research suggests that the model may apply differently depending upon the cultural context (Brossard et al. 2004).

Instead, I would suggest that three broad approaches within the literature on media and society more adequately account, in part, for the complex and shifting nature of this coverage over time through their different and, to some extent, complementary insights: the political economy approach, the structuralist approach and the culturalist approach.

\section{Culture, society and the media}

\section{Political economy}

This approach emphasizes the influence of media ownership, corporate finance and advertising upon news content. Media corporate interests and the vested interests of advertisers, it is argued, may discourage criticism of government's inaction over climate change or industry's role. This may not necessarily occur through direct editorial interference. More often, a dependency on advertising revenue from fossil fuel industries may lead journalists to self-censor their stories so that they are written in ways that do not directly threaten their interests. Gelbspan (2005) documents the case of a television editor who was threatened that oil and car advertising would be withdrawn, following a report being carried which linked a huge flood with climate change. To varying degrees, newspapers devote a significant amount of space to adverts for oil companies, air travel and cars (see Monbiot 2007).

While mainstream media are likely to steer clear of reporting which deeply challenges corporate interests that have a strong connection with their outlets, it would be far too simplistic to suggest that ties with fossil fuels industries completely prevent critical reporting. As Carvalho (2007) observes, there is always some space for a diversity of views to be aired. Indeed, investigative reporting by such journalists as Andy Revkin in the United States and George Monbiot in the United Kingdom have played a key role in exposing the politics of climate science scepticism. For example, in 2005, Andy Revkin of the New York Times uncovered connections between the climate denial industry and the White House. An investigation by the New York Times found that Phillip Cooney, a lawyer with no scientific training and previous lobbyist for the American Petroleum Industry, frequently edited government climate reports to emphasize doubts about the link between climate change and fossil fuel emissions (Monbiot 2006; Revkin 2005).

The Political Economy approach raises familiar questions for sociologists concerning inequalities in power and resources - in this case among news sources. Several scholars have noted how powerful industry groups, special 
interest lobbies and PR companies in the United States have manipulated scientific claims and exploited the news media (e.g. Antilla 2005). An industry group, Global Climate Coalition, was established in 1989 to challenge the scientific basis of global warming. This group, which had 54 industry members, spent huge sums of money on lobbying and public relations. In 1993 alone, one member of this group, the American Petroleum Institute, was reported to have spent $\$ 1.8$ million to a public relations company to try to defeat a proposed tax on fossil fuels (Gelbspan 1995). There have also been very strong links between the oil giant, Exxon Mobil, and climate sceptic think tanks, such as the American Enterprise Institute (Gelbspan 2004). The UK's Royal Society found that in 2005, Exxon Mobil distributed $\$ 3.9$ million to 39 organisations challenging the science of global climate change. Moreover, according to the US Union of Concerned Scientists, between 1998 and 2005, the company contributed almost 16 million dollars to a network of 43 groups that questioned the scientific consensus. In September 2006, the Royal Society wrote a letter to Exxon Mobil demanding it withdraw its support for climate sceptic think tanks. Jacques et al. (2008) conducted a quantitative analysis of 141 English language environmental sceptical books published between 1972 and 2005 and found that over 92 percent were connected to conservative think tanks (CTTs), mainly based in the United States. Moreover, their analysis of 50 think tanks revealed that 90 percent of those concerned with environmental issues supported scepticism in their publications and websites, and all eight think tanks principally interested in climate change adopted a sceptical viewpoint and were based in the United States. A major strategy of the CTTs is to sow the seed of doubts or in their words 'manufacture uncertainty' (2008: 362).

An article in the UK's Guardian newspaper revealed that the American Enterprise Institute, funded by Exxon Mobil, had offered scientists and economists $\$ 10,000$ each as payment for articles designed to undermine the release of an IPCC report (Sample 2007). PR, then, has played a highly significant role in the climate change debate and claims-makers are employing increasingly sophisticated strategies to target the media. As we shall see in the following section, examining the behind-the-scenes battle between news sources is crucial to understanding the pattern and nature of climate change news over time.

\section{Structuralism}

This approach is principally concerned with the concept of ideology and social factors in the production of news, and places particular emphasis upon the relationship between media professionals and their 'sources'. It is interested in how journalists' everyday organisational routines and professional norms impact upon coverage. Organisational routines are, to some degree, based around pre-planned agendas of predictable news items. 
Time acts as a major constraint, predisposing journalists towards institutional sources perceived to be both reliable and trustworthy. The professional norms or 'news values' revolve around novelty, drama, event-centred coverage, personification and the principles of impartiality or balance (Wilkins 1993). Although it shares some points of commonality with the Political Economy Approach, structuralism rejects the view that media content can simply be viewed as determined by economic factors alone.

A variety of studies have shown that the news media tend to follow the political agenda and coverage of climate change is very closely linked to this (e.g. Anderson 1997; Carvalho and Burgess 2005). As Boykoff and Boykoff (2007) observe, the trajectory of global warming coverage does not follow a 'natural' cycle and is strongly connected to policy developments. Social problems compete for attention and issue entrepreneurs or claimsmakers play a key role in generating interest (Hilgartner and Bosk 1988). Interestingly, Trumbo (1996) found a trend from the late 1980s for political rather than scientific sources to dominate coverage in his content analysis of a sample of US national newspapers. It also tends to be event-driven and extreme weather has frequently generated more widespread interest (Carvalho and Burgess 2005; Ungar 1992). A number of peaks in news media coverage have coincided with heat waves or severe flooding which have been perceived to be caused by climate change, giving the issues greater cultural resonance (Mazur 1998). However, evidence suggests that weather is not the single most important determinant of attention to the issues (Shanahan and Good 2000).

Organisational routines and journalistic norms lead to a tendency to overly rely upon authority figures. Stuart Hall et al's seminal study, Policing the Crisis, drew attention to the ways in which official sources (such as government officials and law enforcement agencies) tend to get advantaged access to the news media and as a result become 'primary definers' of key issues (Hall et al. 1978). Through these processes, particular definitions of climate change become privileged (Newell 2000). Both climate scientists and 'contrarians' complain that news media coverage is biased. The contest to gain favourable coverage is not a level playing field since official sources tend to have greater financial resources and stocks of cultural capital News entry for dominant and marginal groups is dependent on numerous contingencies that may be internal or external to the media and shift over time (Anderson 1997).

Many environmental correspondents express a great deal of personal interest in environmental issues but differ in the extent to which they believe they should engage in 'moral partisanship' or 'advocacy'. Typically, they emphasize the values of neutrality but some see it as their duty to inform publics through taking on an advocacy role (Anderson 1997). Where there is overt contestation over a complex issue then journalists frequently lean on the concept of balance and cover 'both' sides of the story. McCright and Dunlap (2003) argue that this practice has resulted 
in the US prestige press producing a biased account of climate change which implies the scientific community are split down the middle. Evidence suggests that 'balanced' coverage may amplify uncertainty and encourage political inaction (Boykoff and Roberts 2007; Corbett and Durfee 2004; McCright and Dunlap 2003; Moser and Dilling 2004). Studies show that US elite newspapers have tended to distort climate science through placing much greater emphasis upon uncertainty than their equivalents in New Zealand, Finland and the United Kingdom (Boykoff 2007a; Dispensa and Brulle 2003). Since 2005, this emphasis on balanced reporting no longer appeared generally evident in the US prestige press (Boykoff 2007a); however, this tendency was still found to be present in a study that examined climate change reporting in the UK popular press between 2000 and 2006 (Boykoff and Mansfield 2008).

One aspect that is often over looked concerns the behind-the-scenes battles which influence whether an issue gets media coverage or not, and how particular actors are portrayed. Gaining access to the media and achieving coverage is only half the battle. Rather than concentrate solely upon quantitative indicators of news media attention to climate change and the prominence of different news actors, we need to consider the terms on which this coverage is secured (Anderson 2006; Murdock et al. 2003; Ryan 1991). Control over the media is as much about the power to silence and suppress issues as it is to publicise them. Moreover, claims-makers are engaged in continual definitional struggles, requiring an in-depth and multi-faceted analysis of the factors influencing the effectiveness of media strategies over time. Examining the degree of space afforded to global warming by different newspapers, and the amount of coverage given to various news sources, while useful, offers an inevitably limited account of representations of climate change within the news media.

Discourse analytic studies offer an in-depth examination of how particular linguistic repertoires are used in news coverage. As Carvalho observes: '... the role of ideology in media representations of science is still blatantly under-researched' (2007: 225). Her study of representations of the climate change debate in the UK quality press offers a particularly insightful analysis of how the ideological standpoints of newspapers, resulting from sharply contrasting value systems, can profoundly shape discourses of scientific knowledge. The credibility given to different social actors such as the IPCC was found to significantly differ among the UK prestige newspapers (Carvalho and Burgess 2005). There are significant variations within the quality press, with The Guardian tending to give by far the most space to climate change issues in the early 2000s (Carvalho and Burgess 2005; Gavin 2007; Hargreaves et al. 2003). Additionally UK-based research suggests that global warming has received considerably greater coverage in the 'quality' press than the mass circulation 'red-top' newspapers (Hargreaves et al. 2003). Indeed, research in media and cultural studies has demonstrated that the news media are complexly differentiated occupying their own particular 
market niches, and governed by a range of economic and political constraints (Anderson 1997). Portrayals differ according to different media formats governed by their own particular restrictions, professional cultures and distinctive ideological standpoints (Carvalho and Burgess 2005). As Carvalho (2007) observes, different newspapers have their own worldviews and values within their organisations which are broadly shared by their specific audiences. However, these ideologies are not adopted in a uniform manner, allowing for a degree of diversity in the range of opinions presented.

\section{Culturalism}

In contrast to the former two approaches, this perspective places less emphasis upon economic factors and news production processes and is more concerned with how cultural norms or 'givens' are embedded within media coverage (Anderson 1997). Attention is drawn to the ways in which particular meanings and discourses are reflected and reinforced within media coverage, calling for in-depth (often qualitative) examination of media texts. Here, the concept of framing is particularly useful. The concept of news framing refers to the 'principles of selection, emphasis, and presentation composed of little tacit theories about what exists, what happens, and what matters' (Gitlin 1980: 6). Frames constitute ways of organising ideas (often highly contested) into meaningful categories and privilege some aspects over others (Entman 1993; Miller and Riechert 2000). A content analysis-based study by Antilla (2005) identified a number of frames within the US press: valid science; ambiguous cause and effects; uncertain science and controversial science. Boykoff (2007b) identified a trend towards the framing of anthropogenic climate science as contentious within a sample of US national press and television news coverage between 1995 and 2006. Moreover, studies identify a tendency towards 'episodic' framing where coverage is linked to specific events or particular cases. By contrast, 'thematic' framing places issues in a wider socio-political context (Boykoff and Boykoff 2007; Boykoff and Roberts 2007). Nisbet and Mooney (2007) note how climate change has been framed in a number of different ways by US politicians; for example, Democrats have tended to use the 'Pandora's Box' of catastrophe metaphor, whilst Republicans have tended to emphasize the money frame and the scientific uncertainty frame.

European studies suggest that the reporting of climate science tends to be alarmist; steeped in the language of fear, catastrophe and disaster (Ereaut and Segnit 2006; Hulme 2007; Peters and Heinrichs 2008). Such fear-based portrayals have been shown to be counter-productive (Bell 1994; Moser and Dilling 2004). Both Hulme (2007) and Ereaut and Segnit (2006) draw upon the concept of 'linguistic repetories'. This may be defined as: '... systems of language that are routinely used for describing and evaluating actions, events and people.' They offer different ways of thinking and talking and act as different versions of what can be considered 'common 
sense.' (Ereaut and Segnit 2006: 7). On the basis of a discourse and semiotic analysis, Ereaut and Segnit identify three main repertoires in the United Kingdom: the 'alarmist repertoire' (pessimistic, seeing climate change as beyond human control), the 'settlerdom' repertoire (optimistic, 'it'll be alright' attitude) and the 'small actions' repertoire (optimistic, if we all do small things we can mitigate the risks). They conclude that media messages tended to be 'confusing, chaotic and contradictory' (2006: 7). More recently, Risbey (2008) identifies the emergence of a fourth strand within the discourse (exemplified in the writings of the UK Guardian journalist, George Monbiot, for example), which sees climate change as alarming if we do not act soon but, if radical steps (both small and large) are taken, it is not beyond our control.

Thus far, the emphasis has tended to be placed on mitigation rather than adaptation. If reporters were to take a thematic as opposed to an episodic approach to covering the issues, this would go some way towards improving the situation (Boykoff and Roberts 2007). The next few years will be crucial as the area becomes increasingly challenging and complex to report. Although coverage of the problem has entered the mainstream, media professionals will need to find new ways to sustain attention over time, particularly when other 'competing' issues such as the economy take precedence.

It should be apparent that there are significant overlaps between these approaches and it is difficult to disentangle the various elements. Moreover, I have concentrated here upon conceptual frameworks that focus upon internal and external constraints affecting the media but it is important to avoid over-playing their role. Whilst pivotal, they constitute only one particular facet of a complex web of influences including social, political, economic and cultural factors. Finally, I conclude by offering some observations about how future research can build upon the advances in knowledge discussed above.

\section{New developments}

\section{Ethnographic research}

Previous research in this field has tended to be media-centric and there is clearly a need for more ethnographic research to explore the processes that shape hierarchies of access to the news media in greater depth (Anderson 2006). This is especially the case for research in a field which has become increasingly politicised and influenced, particularly in the United States, by powerful industry lobbies and special interest groups. What is needed is a systematic analysis of the strategic and tactical action of sources in relation to the media (Anderson 1997). A number of studies have conducted interviews with journalists reporting climate change (e.g. Boykoff and Mansfield 2008; Harbinson et al. 2006; Mormont and Dasnoy 1995; Wilson 2000a,b). However, at the time of writing, a Panos Institute 
study is the only published piece of research to include the perspectives of journalists and media professionals in developing countries (Harbinson et al. 2006). Research involving in-depth interviews with editors and reporters would provide important insights into the factors impeding or enhancing climate change coverage. Few studies have included interviews with scientists about their media relations (exceptions include Boykoff 2007b; Mormont and Dasnoy 1995). Mormont and Dasnoy (1995) represent one of the few pieces of research to include interviews with environmental organisations about their media strategies concerning climate change. Studies involving in-depth interviews with news sources would provide us with a greater understanding of competition to control the issue and the behind-the-scenes factors influencing patterns of reporting.

\section{Cross-cultural research}

As a number of scholars have noted, there needs to be more internationally comparative work (e.g. Boykoff and Boykoff 2004) if we are to understand how different socio-economic, political and cultural contexts shape the reporting of climate science. The foundation for such work has already been laid; for example, Boykoff and Boykoff (2007) compare UK and US coverage; Brossard et al. (2004) provide a comparison of French and US reporting; and Dispensa and Brulle (2003) examine coverage in New Zealand, Finland and the United States. Future research could fruitfully explore the reasons for different levels of coverage in different countries, their different emphases and why the views of developing countries are rarely aired (Painter 2007; Shanahan 2007). There are clearly significant differences between the US news media, for example, and Chinese news media controlled by the State (Tolan 2007). Such research should play an important role in improving communication and help to identify the main barriers towards change. Future studies could also usefully examine the role of global news agencies/wire services since they have been shown to be an important source of information on climate science (Antilla 2005). There is often a considerable amount of recycling of news stories from European and US sources (Boykoff and Roberts 2007: 16). Further work in this area could strengthen our understanding of complex information flows between countries and help us to analyse broader socio-political issues in the reporting of environmental affairs.

\section{Research examining divergences across and within different media outlets}

Within the increasingly international, multi-digital, interactive and fragmented media environment, there is a growing need to examine how competing rationality claims are framed by different media, given that they are complexly differentiated and governed by different economic, political and organisational constraints. Early studies tended to focus mainly 
on the US prestige press and until recently very few studies included an analysis of popular mass-market newspapers. In the United Kingdom, such newspapers are widely known for their partisan coverage. Over the last two decades, there has been a steep decline in the readership of these 'popular' newspapers in the United Kingdom (Curtice and Mair 2008). Nevertheless, it is still important to know more about the ways in which they frame climate science, and the visibility or lack of visibility of the issue, given their share of the market in relation to the 'quality press'. Hulme, for example, found that the IPCC reports generally received very little coverage in the UK popular press the day following their publication; one newspaper, The Daily Star, made no mention of any of them at all (Hulme 2007). Few studies have included an analysis of regionally based newspapers; yet, they play a potentially significant role in influencing public perceptions and action and need to be explored further.

Thus far, relatively little research in this field has focused upon television, despite its importance as a trusted source of information (Ungar 1992; Wilson 1995). As with the field of risk research more generally this is largely due to practical constraints, and most work has concentrated upon factual rather than fictional media (Murdock et al. 2003). Also, despite the growing importance of the Internet as a source of news about science, only a handful of studies have systematically examined web-based representations of climate change (see Horrigan 2006; Ladle et al. 2005). The decline of traditional news and the growing importance of blogs, listservs, online publications, podcasts etc. and proliferation of news sources have important implications for the communication of climate change (Anderson and Marhadour 2007).

Such developments raise questions about who controls access to news and how far the media are becoming dependent upon international news agencies and public relations companies. The Internet provides a host of conflicting claims about climate change and therefore offers a particularly useful research site. Indeed, a Panos Institute study that interviewed journalists in Sri Lanka, Honduras, Jamaica and Zambia found that the Internet was named as their most important source of information on climate change issues (Harbinson et al. 2006: 11). Future studies are likely to reflect changes in media consumption including the declining influence of the newspaper press and the growing use of the Internet and mobile phones, particularly among young people (Dutton and Helsper 2007). Advances in technology should enable researchers to more easily study information flows between the newspaper press, digital television, and the Internet as they become more integrated.

\section{Research on messages and meanings in popular culture}

More research on representations of global warming within popular culture, particularly in relation to celebrities, would be useful. The involvement 
of celebrities is increasingly becoming a means through which the newsworthiness of environmental stories is enhanced (Anderson et al. 2005). Moreover, the work of science fiction writers, such as Michael Crichton (author of State of Fear), have been demonstrated to influence public policy arenas (Petersen et al. 2005). This novel provided a means through which oppositional voices on climate science could gain access to the policymaking sphere (Boykoff and Boykoff 2007). Future research could examine the different ways in which climate change is framed within popular culture and the blurring of fact and fiction. This would aid our understanding of the different kinds of representations of climate change which may have very different sorts of meanings for different groups of people.

\section{Research on visual imagery in the climate change debate}

Finally, there is also a need for research on the use of visual imagery since very few studies have examined this in relation to climate change (a notable exception is Doyle 2007). This includes images used both by the media and by a range of news actors in their communications campaigns. Previous research suggests that emotive images of risk can become powerful icons (Anderson 1997). However, the long-term nature of global warming and lack of visibility have clearly contributed to problems in sustaining media interest over time. A former Environment Correspondent for BBC News observed: 'Above all environmental stories really need good pictures ... global warming is very difficult because you can't actually see global warming.' (Interview, November 1990, quoted by Anderson 1997: 121-2). Future research could usefully explore how different audiences interpret a range of widely circulated images of climate change as this would help to establish their usefulness and how messages about climate change could best be developed and targeted in the future.

\section{Conclusions}

This review of the existing literature demonstrates that this is an important, developing field of interest to researchers within a wide range of disciplines. It highlights how media reporting of climate change is heavily influenced by socio-political factors over time, and has become increasingly affected by political and industry interests. Media professionals are faced with multiple challenges in covering this complex field and there is an urgent need to uncover the 'behind-the-scenes' factors that shape current representations. So far, the emphasis within news media coverage has tended to be on mitigation rather than adaptation. Some evidence suggests that the growing concentration and globalisation of news media ownership has led to an emphasis upon human interest, celebrity-focused entertainment style reporting which discourages headline reporting of 
complex, multi-faceted issues such as climate change. If reporters were to take a thematic as opposed to an episodic approach to covering the issues, this would go some way towards improving the situation. While climate change has firmly entered mainstream news media agendas, media practitioners will need to find new ways to sustain attention over time.

There is considerable scope for sociology to make a greater contribution towards understanding these issues. As I have argued, climate change connects with key debates within the discipline concerning knowledge, risk and power. The media are central to the mediation of what Beck refers to as the 'relations of definition' between the scientific, political and public spheres. I have suggested an agenda of media research on climate change which would involve sociologists in collaboration with other researchers from different disciplines such as human geography and environmental sciences. It is hoped that this research will generate new ways of addressing the complex cultural processes through which we come to understand one of the most pressing issues of our time.

\section{Short Biography}

Alison Anderson is Reader in Sociology in the School of Law and Social Science, University of Plymouth, UK. She is the author of Media, Culture and the Environment (Routledge/Rutgers University Press, 1997) and co-author of Nanotechnology, Risk and Communication (Palgrave Macmillan, in Press), and has published numerous journal articles on the reporting of environmental issues. She is currently writing Media, Environment \& the Network Society (Palgrave Macmillan 2009).

\section{Note}

* Correspondence address: School of Law and Social Science, University of Plymouth, Drake Circus, Plymouth PL4 8AA, UK. E-mail: aanderson@plymouth.ac.uk

\section{References}

Anderson, Alison 1997. Media, Culture and the Environment. London, UK: UCL Press.

Anderson, Alison 2006. 'Media and Risk.' Pp. 114-31 in Beyond the Risk Society, edited by Sandra Walklate and Gabe Mythen. Milton Keynes, UK: Open University/McGraw Hill. Anderson, Alison and Agnes Marhadour 2007. 'Slick PR? The Media Politics of the Prestige Oil Spill.' Science Communication 29: 96-115.

Anderson, Alison and Ivor Gaber 1993. 'The Yellowing of the Greens.' British Journalism Review 4: 49-53.

Anderson, Alison, Alan Petersen, Stuart Allan and Clare Wilkinson 2005. 'The Framing of Nanotechnologies in the British Newspaper Press.' Special Issue of Science Communication 27: 200-20.

Antilla, Lisa 2005. 'Climate of Scepticism: US newspaper Coverage of the Science of Climate Change.' Global Environmental Change 15: 338-52.

Beck, Ulrich 1992. Risk Society: Towards a New Modernity. London, UK: Sage.

Bell, Allan 1994. 'Media (Mis) Communication on the Science of Climate Change.' Public Understanding of Science 3: 259-75. 
Boykoff, Maxwell T. 2007a. 'Flogging a Dead Norm? Newspaper Coverage of Anthropogenic Climate Change in the USA and UK from 2003-2006.' Area 39: 470-81.

Boykoff, Maxwell T. 2007b. 'From Convergence to Contention: United States Mass Media Representations of Anthropogenic Climate Change Science.' Transactions of the British Institute of Geographers 32: 477-89.

Boykoff, Maxwell T. 2008. 'Lost in Translation? United States Television News Coverage of Anthropogenic Climate Change, 1995-2004.' Climate Change 86: 1-11.

Boykoff, Maxwell T. and Jules M Boykoff 2004. 'Balance as Bias: Global Warming and the US Prestige Press.' Global Environmental Change 14: 125-36.

Boykoff, Maxwell T. and Jules M. Boykoff 2007. 'Climate Change and Journalistic Norms: A Case Study of US Mass-Media Coverage.' Geoforum 38: 1190-204.

Boykoff, Maxwell T. and J. Timmons Roberts 2007. 'Media Coverage of Climate Change: Current Trends, Strengths, Weaknesses.' Human Development Report 2007/8, United Nations Development Programme Occasional paper, Human Development Report Office.

Boykoff, Maxwell T. and Maria Mansfield 2008. 'Ye Olde Hot Aire: Reporting on Human Contributions to Climate Change in the UK Tabloid Press.' Environmental Research Letters 3: 8.

Brossard, Dominique, James Shanahan and Katherine McComas 2004. 'Are Issue-Cycles Culturally Constructed? A Comparison of French and American Coverage of Global Climate Change.' Mass Communication \& Society 7: 359-77.

Carvalho, Anabela 2007. 'Ideological Cultures and Media Discourses on Scientific Knowledge: Re-reading News on Climate Change.' Public Understanding of Science 16: 223-43.

Carvalho, Anabela and Jacquelin Burgess 2005. 'Cultural Circuits of Climate Change in the UK Broadsheet Newspapers, 1985-2003.' Risk Analysis 25: 1457-70.

Corbett, Julia. B. and Jessica L. Durfee 2004. 'Testing Public (Un)Certainty of Science: Media Representations of Global Warming.' Science Communication 26: 129-51.

Curtice, John and Ann Mair 2008. 'Where Have All the Readers Gone? Popular Newspapers and Britain's Political Health.' Pp. 161-72 in British Social Attitudes 24th Report, edited by Alison Park et al. London, UK: Sage.

Dispensa, Jaclyn Marisa and Robert J. Brulle 2003. 'Media's Social Construction of Environmental Issues: Focus on Global Warming - a Comparative Study' International Journal of Sociology and Social Policy 23: 74-105.

Downs, Anthony 1972. 'Up and Down with Ecology: The "Issue Attention Cycle". Public Interest 28: 38-50.

Doyle, Julie 2007. 'Picturing the Clima(c)tic: Greenpeace and the Representational Politics of Climate Change Communication.' Science as Culture 16: 129-50.

Dunwoody, Sharon 2007. 'The Challenge of Trying to Make a Difference Using Media Messages.' Pp. 89-104 in Creating a Climate for Change: Communicating Climate Change and Facilitating Social Change, edited by Suzanne C. Moser and Lisa Dilling. Cambridge, UK: Cambridge University Press.

Dutton, William and Ellen Helsper 2007. Oxford Internet Survey 2007 Report: The Internet in Britain. Oxford, UK: Oxford Internet Institute.

Entman, Robert M. 1993. 'Framing: Towards Clarification of a Fractured Paradigm.' Journal of Communication 43: 51-8.

Ereaut, Gill and Nat Segnit 2006. Warm Words: How are we Telling the Climate Story and Can we Tell it Better? London, UK: Institute for Public Policy Research. http://www.countryguardian.net/ warm_words.pdf (Last accessed 02/10/07).

Gavin, Neil T. 2007. 'Global Warming and the British Press', Unpublished paper presented at Political Studies Association Conference, University of West England, Bristol, September.

Gelbspan, Ross 1995. 'The Heat is On: The Warming of the World's Climate Sparks a Blaze of Denial.' Harpers Magazine, December.

Gelbspan, Ross 2004. Boiling Point. New York, NY: Perseus.

Gelbspan, Ross 2005. Snowed: Why is the US Media Silent on Global Warming? Mother Jones online publication. http://www.motherjones.com/cgi-bin/print_article.pl?url=http:// www.motherjones.com/news/feature/2005/05/snowed.html (Last accessed 15/07/08).

Gitlin, Todd 1980. The Whole World is Watching: Mass Media in the Making and Unmaking of the New Left. Berkeley, CA: University of California Press. 
Hall, Stuart, Charles Critcher, Tony Jefferson, John Clarke and Brian Robert 1978. Policing the Crisis: Mugging, the State and Law and Order. London, UK: Macmillan.

Harbinson, Rod, Richard Mugara and Ambika Chawla 2006. Whatever the Weather: Media Attitudes to Reporting Climate Change. London, UK: Panos Institute. http:// www.panos.org.uk/PDF/reports/whatevertheweather.pdf (Last accessed 10/12/2007).

Hargreaves, Ian, Justin Lewis and Tammy Speers 2003. Towards a Better Map: Science, the Public and the Media. Swindon, UK: Economic and Social Research Council Report. http:// www.esrc.ac.uk/ESRCInfoCentre/Images/Mapdocfinal_tcm6-5505.pdf (Last accessed 10/ 12/2007).

Hilgartner, Stephen and Charles L. Bosk 1988. 'The Rise and Fall of Social Problems: A Public Arenas Model.' American Journal of Sociology 94: 53-78.

Horrigan, John 2006. The Internet as a Resource for News and Information about Science. Washington, UK: Pew Internet and American Life Project. http://www.pewinternet.org/pdfs/ PIP_Exploratorium_Science.pdf

Hulme, Mike 2007. 'Mediated Messages about Climate Change: Reporting the IPCC Fourth Assessment in the UK Print Media.' Science Communication. http://www.mikehulme.org/ wp-content/uploads/2007/09/hulme-all-mediated-messages.pdf (Last accessed 02/10/07).

Jacques, Peter J., Riley E. Dunlap and Mark Freeman 2008. 'The Organisation of Denial: Conservative Think Tanks and Environmental Scepticism.' Environmental Politics 17: 349-85.

Kirby, Alex 2001.'The Media and Climate Change'. Keynote speech, Alliance for the Sustainability Transition, The European Climate Forum, Potsdam 3-4 October.

Ladle, Richard, Paul Jepson and Robert J. Whittaker 2005. 'Scientists and the Media: The Struggle for Legitimacy in Climate Change and Conservation Science.' Interdisciplinary Science Review 30: 231-40.

Leggett, Jeremy 2001. The Carbon War: Global Warming and the End of the Oil Era. London, UK: Routledge.

Lever-Tracy, Constance 2008. 'Global Warming and Sociology' Current Sociology 56: 445-66.

Mazur, Alan 1998. 'Global Environmental Change in the News: 1987-90 Vs 1992-96.' International Sociology 13: 457-72.

McComas, Katherine and James Shanahan 1999. 'Telling Stories about Global Climate Change.' Communication Research 26: 30-57.

McCright, Aaron M. and Riley E. Dunlap 2003. 'Defeating Kyoto: The Conservative Movement's Impact on U.S. Climate Change Policy.' Social Problems 50: 348-73.

Miller, Mark M. and Bonnie Parnell Riechert 2000. 'Interest Group Strategies and Journalistic Norms: News Media Framing of Environmental Issues.' Pp. 45-54 in Environmental Risks and the Media, edited by Stuart Allan, Barbara Adam and Cynthia Carter. London, UK: Routledge.

Monbiot, George 2006. Heat: How to Stop the Planet from Burning. London, UK: Random House.

Monbiot, George 2007. 'The Editorials Urge Us to Cut Emissions, But the Ads Tell a Very Different Story.' The Guardian August 14th.

Mormont, Marc and Christine Dasnoy 1995. 'Source Strategies and the Communication of Climate Change.' Media, Culture and Society 17: 49-64.

Moser, Suzanne C. and Lisa Dilling 2004. 'Making Climate Hot: Communicating the Urgency and Challenge of Global Climate Change.' Environment 46: 32-46.

Murdock, Graham, Petts Judith and Tom Horlick-Jones 2003. 'After Amplification: Rethinking the Role of the Media in Risk Communication.' Pp. 156-78 in The Social Amplification of Risk, edited by Nick Pidgeon, Roger Kasperson and Paul Slovic. Cambridge, UK: Cambridge University Press.

Newell, Peter 2000. Climate for Change: Non-State Actors and the Global Politics of the Greenhouse. Cambridge, UK: Cambridge University Press.

Nisbet, Matthew and Chris Mooney 2006. 'The Next Big Storm: Can Scientists and Journalists Work Together to Improve Coverage of the Hurricane-Global Warming Controversy?' Sceptical Inquirer, August 3rd. http://www.csicop.org/scienceandmedia/hurricanes/ (Last accessed 10/ 02/2008).

Nisbet, Matthew and Chris Mooney 2007. 'Science and Society: Framing Science.' Science 316: 56. 
Painter, James 2007. 'All Doom and Gloom? International TV Coverage of the April and May 2007 IPCC Reports.' http://www.eci.ox.ac.uk/news/events/070727-carbonundrum/painter.pdf

Peters, Hans Peter and Harold Heinrichs 2008. 'Legitimizing Climate Policy: The "Risk Construct" of Global Climate Change in the German Mass Media.' International Journal of Sustainability Communication 3: 14-36. http://www.ijsconline.org/docs/artikel/03/3_04_IJSC_ Research_PetersHeinrichs.pdf

Petersen, Alan, Alison Anderson and Stuart Allan 2005. 'Science Fiction/Science Fact: Medical Genetics in News Stories.' New Genetics \& Society 24: 337-53.

Revkin, Andrew 2005. 'Bush Aide Softened Greenhouse Gas Links to Global Warming.' New York Times, June 8th.

Risbey, James S. 2008. 'The New Climate Discourse: Alarmist or Alarming?' Global Environmental Change 18: 26-37.

Ryan, Charlotte 1991. Prime Time Activism: Media Strategies for Grassroots Organizing. Boston, MA: South End Press.

Sachsman, David 2000. 'The Role of the Mass Media in Shaping Public Perceptions and Awareness of Environmental Issues,' Climate Change Communication Conference, Ontario, Canada, 22-24 June. In Climate Change Communication: Proceedings of an International Conference, edited by Daniel Scott. Waterloo: University of Waterloo. http://dsp-psd.pwgsc.gc.ca/ Collection/En56-157-2000E.pdf (Last accessed 10/02/2008).

Sample, Ian 2007. 'Scientists Offered Cash to Dispute Climate Study'. The Guardian, February 2nd. http://www.guardian.co.uk/environment/2007/feb/02/frontpagenews.climatechange (Last accessed 10/02/2008).

Shanahan, James and Jennifer Good 2000. 'Heat and Hot Air: Influence of Local Temperature on Journalists' Coverage of Global Warming.' Public Understanding of Science 9: 285-95.

Shanahan, Mike 2007. Talking about a Revolution: Climate Change and the Media: An International Institute for Environment and Development Briefing. IIED, December.

Stamm, Keith R., Fiona Clark and Paula Reynolds Eblacas 2000. 'Mass Communication and Public Understanding of Environmental Problems: The Case of Global Warming.' Public Understanding of Science 9: 219-37.

Tolan, Sandy 2007. Coverage of Climate Change in the Chinese Media. Human Development Report 2007/8. http://hdr.undp.org/en/reports/global/hdr2007-2008/papers/tolan_sandy.pdf

Trumbo, Craig 1996. 'Constructing Climate Change: Claims and Frames in US News Coverage of an Environmental Issue.' Public Understanding of Science 5: 269-83.

Trumbo, Craig and James Shanahan 2000. 'Social Research on Climate Change: Where we have Been, Where we Are and Where we Might Go.' Public Understanding of Science 9: 199204.

Ungar, Sheldon 1992. 'The Rise and (Relative) Decline of Climate Change as a Social Problem.' The Sociological Quarterly 33: 483-501.

Weingart, Peter, Anita Engels and Petra Pansegrau 2000. 'Risks of Communication: Discourses on Climate Change in Science, Politics and the Mass Media.' Public Understanding of Science 9: 261-83.

Wilkins, Lee 1993. 'Between the Facts and Values: Print Media Coverage of the Greenhouse Effect 1987-1990.' Public Understanding of Science 2: 71-84.

Wilson, Kris M. 1995. 'Mass Media as Sources of Global Warming Knowledge.' Mass Communication Review 22: 75-89.

Wilson, Kris M. 2000a. 'Drought, Debate, and Uncertainty: Measuring Reporters' Knowledge and Ignorance about Climate Change.' Public Understanding of Science 9: 1-13.

Wilson, Kris M. 2000b. 'Communicating Climate Change through the Media: Predictions, Politics and Perceptions of Risk.' Pp. 201-17 in Environmental Risks and the Media, edited by Stuart Allan, Barbara Adam and Cynthia Carter. London, UK: Routledge. 